\title{
Mobile Phones Help Develop Listening Skills
}

\author{
Galina Artyushina *(i) and Olga A. Sheypak \\ Department of Foreign Languages, MAI-National Research University, Moscow 121552, Russia; \\ oasheypak@gmail.com \\ * Correspondence: gartyushina@gmail.com; Tel.: +7-903-689-9824
}

Received: 29 April 2018; Accepted: 25 July 2018; Published: 27 July 2018

\begin{abstract}
Listening is one of the most difficult language skills among the four communication competences; however, it has received much less time in English learning than the other three (reading, writing, and speaking). Also, listening is often claimed to be a passive skill in the classroom, as learners seem to sit quietly and listen to dialogues. As language teachers, we are constantly striving to create the conditions under which our students can learn and succeed. At the same time, we meet challenges that may be detrimental to the learning process. This certainly applies to mobile phone use on the part of our students. It is a well-known fact that practically every student has at least one mobile device, as it has become a very convenient tool to get information. Unfortunately, students still prefer to use smart devices as entertainment, either to listen to music, watch films, or play computer games; it seems they really do not know how to use them in the process of education. This paper presents a review of how to get over difficulties in listening, and develop listening skills with the help of mobile phones outside the classroom. We have realized that to study English using mobile phones can consolidate our students' understanding of what is being presented, or further contextualize the language to improve their ability to use it in communicative practice. To study English supposes this process to be non-durable, i.e., not only in the classroom under the guidance of the teacher. So, to study with the help of mobile technologies and handheld gadgets is a good opportunity to improve the quality and effectiveness of English learning.
\end{abstract}

Keywords: listening skills; mobile phones; communication competence; self-studies

\section{Introduction}

The fact of the matter is that mobile phones are a very real and important part of everyday life. In fact, people nowadays have a strong dependence on their mobile phones, whether they are aware of it or not. Therefore, why should we not make the best of the situation and allow for the effective use of mobile phones to study, especially if they can contribute so much to the learning process? Ultimately, the digital natives in our classrooms will expect us to understand and meet their expectations regarding the use of technology. Mobile learning (m-learning) is gradually being introduced in the field of English language learning. Listening and speaking are the most difficult for students, although a person engaged in communication devotes $30 \%$ of his / her time to speaking and $45 \%$ to listening [1]. Podcasts as a form of innovation technology are a means by which mobile phones can improve listening skills. They also allow a gradual transition to occur, from the state of a passive listener and doer of the comprehension tasks to a creator of podcasts, and give a birth to a new mobile technology in developing and improving both listening and speaking skills.

This paper presents a review of studies on the integration of mobile phones in English language learning through podcasts in the Russian Technical University. It has been divided into six sections, including the introduction. Section 2 contains a review of the sources of the difficulties in listening for technical students in Russia. Sections 3 and 4 propose the use of podcasts via mobile phones in 
self-studies to develop listening skills in English language learning. The five-year experience of the using new mobile technology: podcasts via mobile phones is analysed in Section 5. Lastly, Section 6 concludes the paper and proposes some potential future steps.

\section{Why Listening Is Difficult for Technical Students in Russia}

Listening is one of the most difficult competences in English language learning, as listening is the only kind of speech activity where practically nothing depends on the listening person [1-4]. We have analysed references relating to listening comprehension and difficulties arising in listening [5-7]. These papers outline potential problems that could hinder listening comprehension during English language learning in classrooms. In general, they include the speed delivery, impossibility for learners to have words repeated, the small size of the learner vocabulary, inability to recognize the signals that the speaker is using to move from one point to another, incapability to concentrate in a foreign language, etc. As we have introduced listening for self-studies via mobile phones outside the classroom, we have also carried out research to outline difficulties our students face in listening. We have divided the variety of these difficulties into four main groups.

(1) Difficulties connected with the peculiarities of the listening process and speech activity of a listener.

(2) Difficulties connected with the speech of a native speaker.

(3) Difficulties connected with the traditions and culture of the studied language country.

(4) Difficulties connected with the composition of the recording.

Let's consider them in the order of appearance.

It is a well-known fact that any activity, including speech, is comfortable for the doer if it corresponds with his or her abilities or if he/she is able to adjust to it, i.e., if a speaker chooses a topic for conversation which is interesting to him. In this case, a listener has to get the information a speaker gives. Sometimes the topic is not familiar, and is too difficult for a listener. Usually, a native speaker does not adjust his language to his listener, so the latter has to understand speech with a certain proportion of unknown materials. Moreover, contrary to a reader, a listener can neither listen to the message repeatedly nor use any reference literature to help himself.

The second group of difficulties is connected with the fact that the speech rate of a native speaker often seems too rapid to a foreigner. So, a listener is not able to repeat the message, and that is why he does not interpret it correctly. Moreover, it is a well-known fact that a listener prefers a rate of speech that corresponds to the rate of his mother tongue, which is normally slower. The process of hearing is unique and continuous; the listener can neither stop, nor listen to the message again. Hence, he has to get the message continuously, and only once. It is obvious that in such conditions, it is rather difficult to receive information, and that is why it is only partially understood. It is also shown [8] that low male voices are perceived as being easier than females' and kids' voices, as the latter have much higher tones.

Next, we look at an example of a paradox in listening. It is amazing but true: a Russian pupil understands the English speech of his teacher and classmates, and as a rule, the English speech of his countrymen, while at the same time, he understands English native speakers poorly. What is the reason? The first is that nowadays, the speech of native speakers differs considerably from written language, and tends to be less formal. The second is that the individual style of the oral speech, including its rate, can be rather varied, making speech difficult to be understood. In the mother tongue, this problem is compensated for by a huge amount of listening practice. This experience allows an accumulation in our memory of the majority of different variants of voices and peculiarities in pronunciation. Because of such experiences in listening to a foreign speech, including the fact that more often, a pupil listens to the same native speaker, individual voice peculiarities of native speakers such as their pronunciation, voice timbre, and rapid speech rate make it difficult to understand them. 
The third group of difficulties derives from one of the main principles of communicative competence, that claims that language, being a phenomenon of a certain civilization, should be studied in the context of this civilization. That is why pupils should know the culture of the foreign country. To master a foreign language, one should be aware of the rules of the foreign language in different everyday situations and professional areas. A pupil should perceive and understand an oral message from the position of cross-cultural communication.

Effectiveness in listening also depends on whether students are interested in understanding or not. Experiments have shown [9] that students understand and memorise better texts which are difficult but rich in context compared to easy and primitive ones. Rich content texts contain new and useful information, but problems in understanding these texts will remain. That is because they usually contain facts connected with the history, ways of life, and the culture of the foreign country. These are so-called realities that are often unknown to students. Results have shown [10] that among them are geographical names, proper names, the names of the organisations, the press and works of fiction, and also historical facts, political and military terminology, and terminology connected with various fields of art, pithy sayings and expressions, and quotations from fiction. Moreover, topic action in the recording also influences its understanding.

Sometimes, difficulties in listening can be caused by the composition of the oral text. So the absence of the introduction of the protagonists, the venue and time of the events, several subject lines at the same time in one recording, etc., cause additional trouble for students.

\section{The Integration of Mobile Learning into Self-Studies}

Information technologies penetrating into all spheres of people's activities are characteristic of modern society. That is why information technologies in education are an integral part of this process too [11]. Rapid advances in information and communication technologies have caused a rise in mobile technologies. Society has readily accepted mobile technologies and integrated them. At the moment, there are about 1.5 billion mobile phones, but only 500 million traditional computers in the world [12]. The technical progress gives mobile devices new technical opportunities.

A review of the traditions in teaching English $[13,14]$ has shown that this process was always closely connected with technical equipment. These are language laboratories to help students to develop different skills in listening, speaking, reading, grammar, and vocabulary. Also, electronic programmes and dictionaries have become very popular in combination with numerous audio and video courses. So nowadays, there are many different ways to teach a foreign language using information technologies and technical devices. But the use of new mobile technology in education offers new learning experiences and flexibility in learning-learning anywhere and anytime-with increased opportunities for decisions to be made by learners. Furthermore, mobile technologies offer ubiquitous and immediate access to information, as well as saving resources. The integration of mobile technologies to learn has given a rise to the term "mobile learning", which is often abbreviated to "m-learning". There are many examples of definitions of m-learning [15]; the most general is learning via handheld devices that are potentially available anytime and anywhere.

In Russia, the idea of integrating mobile learning has become prominent after the transition to a three-level system in higher education This transition coincided with the new generation of students growing up in the internet environment, and significant increase of academic hours allocated to self-studies in some technical universities (Table 1).

Table 1. Distribution of the academic hours in English in Master programmes in "MATI-Russian State Technological University".

\begin{tabular}{ccc}
\hline Year & Before 2013 & After 2013 \\
\hline Academic hours for auditorium classes & $52 \%$ & $22 \%$ \\
Academic hours for self-studies & $48 \%$ & $78 \%$ \\
\hline
\end{tabular}




\section{Podcasts as a Motivating Tool in Developing Listening Skills}

An increase of self-study hours has urged teachers to restructure working programs and curricula so that students are engaged more in self-study under the guidance of their teachers. We have chosen podcasts as a mobile technology, as they have great educational potential in developing students' listening and speaking skills $[12,16]$. Podcasting is a technology that allows learning from authentic materials about burning issues of today and current events; they can easily be downloaded from the Internet onto mobile devices with MP3 applications, and listened to when convenient. Podcasts appear to be creative and entertaining on the one hand, and very motivating educational tools on the other. They carry great value for foreign language teaching as internet resources, because they:

(1) are quickly and regularly updated,

(2) may be available any time on mobile devices.

There are different genres in podcasts: audio blogs, music, technology, audiobooks, academic podcasts, interviews, news, policy, radio shows, sport, and games.

The popularity of podcasts has increased markedly: in 2004, there were 840,000 podcast users, but in 2010, their number went up to 60 million. This number is continuing to rise rapidly. Moreover, $75 \%$ of the audience were owners of digital audio players [12].

Academic podcasts to study English as a second language started in Russia in 2008, and solved a number of problems as an unusual technology to develop listening and speaking skills. This technology is considered to motivate students [17]. As academic podcasts introduce diversity in the process of learning English, they arouse real interest among students; this has been proven by some researchers [15]. Also, podcasting provides flexibility, user control, mobility, and allows for time-shifting and multitasking [10].

\section{Results and Discussion}

We have been working with podcasts since 2010. In choosing internet resource materials, we aimed at the various topics that correlated with the main issues in student textbooks. The podcasts must be of the same format for intermediate students. Also, it was a very important for us that the podcasts were recorded both by English native speakers, and at the same time, teachers of the English language. Moreover, while choosing podcasts, special attention was devoted to their duration and the speech rate of the speakers.

Speech rate is one of the decisive factors, especially in ESL (English as a Second Language). We have also taken into consideration the fact that hearing rate is very important [18]. The listening material should be perceived fully and easily, as success in this regard can motivate students to work further with podcasts.

The differences in speech and hearing rates between the Russian and English languages have led to the conclusion that listening would be more effective if there are the same audio materials but with two different rates of the speaker's speech (Table 2). We analysed internet resources from different educational sites; the results are in Table 3.

Table 2. Differences between speed and hearing rate in languages.

\begin{tabular}{ccc}
\hline Rates & Russian Language (wpm) & English Language (wpm) \\
\hline Low speech & $60-80$ & $90-100$ \\
Normal speech & $100-110$ & $140-150$ \\
Everyday speech life & $120-140$ & $160-200$ \\
Hearing rate & $130-170$ & $180-240$ \\
\hline
\end{tabular}


Table 3. The description of the different educational sites.

\begin{tabular}{ccc}
\hline Site & Rate of Speech (wpm) & Duration (min) \\
\hline www.britishcouncil.org/learnenglish & 143 & 7 \\
http://www.bbc.com/learningenglish & 147 & $2-10$ \\
https://deepenglish.com & 100 and 150 & 4 \\
http://eslpod.com & 100 and 150 & 20 \\
\hline
\end{tabular}

There is no doubt that it is rational to choose short recordings for listening during auditorium classes. But as far as self-studies are concerned, more continuous recordings are more effective. That is why, for example, our students are given a month or a month and a half to be ready with the podcasts they do at home.

All these requirements were satisfied by the educational site, www.eslpod.com [19]. We were looking for materials there to help our students avoid various difficulties in listening.

One of the advantages of these podcasts was their strict structure-as any podcast, it has an introduction, a main part and a conclusion. The main part consists of three similar parts of about the same duration. At the beginning of the main part of the podcast, the authors-Dr Jeff McQuillan and Dr Lucy Tse-present a training dialogue or text on the subject, spoken at a slow rate of speech. Then, at the same speech speed, Dr Jeff McQuillan gives explanations of the words and expressions from the recording, i.e., what they mean and how to use them. At the end of this main part, there is again the same training dialogue or text, but now at a normal rate of speech. The introduction is given at the slower speed, while the conclusion is recorded at the rapid rate of speech. Different recording speeds allow students to adjust to the English language phonation and improve their skills to perceive audio materials and sequentially move on to perceive English speech in everyday life [10].

As the podcasts have been chosen as the basis for student self-studies outside the classrooms to increase effectiveness, we worked out an educational supply for students' "Guide to Listening", including a detailed pattern on how to work with the podcast, a workbook with comprehension tasks, instructions, a reference guide with key answers, and a student's guide list [20].

In 2012, we started our project involving about 800 first-year bachelors students, and in 2014, we already accumulated some experience in m-learning [16]. At the beginning of the project, we faced an unexpected problem: it occurred that the majority of the students $(63 \%)$ used only their home PC's to listen to podcasts. When we analysed the reason for this phenomenon, we realised that it was because they do their homework at home, and so they need their PCs. Answering the question of why they didn't use the mobile device that they have at their disposal, our students gave a very simple answer: that they don't know how to use them to listen to podcasts. This answer led to the following conclusion: yes, practically all first-year students have been using different mobile devices since their childhood, but only for entertainment; mostly watching films and cartoons, playing games. But nobody had taught them how to use these devices for self-study. We appeared to be the first to do this.

High-speed mobile Internet has revived podcast technology. It has become possible to listen to podcasts not only by means of audio players, but also on mobile phones and tablets based either on iOS, Android, and Windows. Modern life makes youths adjust to its new rhythm. Students have a lot of opportunities to study outside: they can listen to podcasts anywhere and at any time they want, sometimes using even one headphone (as stereo is not so important in podcasts).

In 2016, our students from the Master programme began to record their own podcasts in English. It was these students who have been working with podcasts at our Department of Foreign Languages since 2012. The fact that to master spoken patterns in Business English is given too little time in the curricula (Table 1) urged us to include this task in Masters-level podcasts. So, using a strict structure of the pattern podcast (Table 4) and reproducing authentic materials from eslpod.com podcasts allowed our students to realize their skills in successful communication, recording their own podcasts on the following topics: "Cross-Cultural Differences in Communication", "Telephoning in Business", 
"Business Presentations", "Meetings in Companies", "Business Negotiations" and others from the Business English Language course.

Table 4. The structure of the podcast.

\begin{tabular}{ccc}
\hline The Part of the Podcast & Duration (\%) & Rate of Speech (wpm) \\
\hline Introduction & 7.5 & 100 \\
Main part (a text or a dialogue) & 10 & 100 \\
Vocabulary and grammar explanation from the general part & 72.5 & 100 \\
The replay of the general part & 7.5 & 150 \\
Conclusion & 2.5 & 250 \\
\hline
\end{tabular}

We have found one more advantage of this work: many of our students had difficulties with public speaking. Now they have a chance to overcome these obstacles by recording their public presentations in MP3 format and sending them to their language teacher using a mobile phone. In return, the teacher sends a student his/her comments to correct mistakes. Such an approach facilitates monitoring the progress in speaking, and building up a sound-recording portfolio for each student.

\section{Conclusions and Future Work}

In conclusion, this paper has reviewed difficulties in listening and how podcasts via mobile phones help to address them outside the classroom. The mobile phone can serve as a "portal" of sorts, expanding our students' vision of what they see, feel, or hear through the use of podcasts. This means that teachers should not rely on the activities and tasks that are presented in the podcast in a "classical" way, but rather, constantly find ways to enhance content, with their own creative twist. Mobile phones can serve that purpose well. The topics presented in podcasts may provide the perfect reason for students to use their mobile phones and complement what they are doing or learning as the part of the main lesson. We plan to continue our project, and further, to include the recordings of the podcasts, made by Masters and Post-graduate students devoted to the main issues of their original scientific research as an integral part of their portfolio. The importance of students making their own podcasts based on their scientific research is obvious: they become a part of the language portfolio of the future specialist, provide students with personal, educational and career development, and enhance their competitiveness. In addition, such experience will help them master the different types of communication which are demanded by national and foreign companies.

Author Contributions: All authors conceived, designed and performed the experiments; analyzed the data and wrote the paper.

Funding: This research received no external funding.

Conflicts of Interest: The authors declare no conflict of interest.

\section{References}

1. Van Duzer, C. Improving ESL Learners' Skills: At the Workplace and Beyond; National Clearinghouse for ESL Literacy Education: Washington, DC, USA, 1997.

2. Nunan, D. Listening in Language Learning. Available online: http://www.jalt-publications.org/tlt/files / 97/sep/nunan.html (accessed on 12 April 2018).

3. Kurita, T. Issues in second language listening comprehension and the pedagogical in implications. Accent. Asia 2012, 5, 30-44.

4. Vandergrift, L. Recent developments in second and foreign language listening comprehension research. Lang. Teach. 2007, 40, 191-210. [CrossRef]

5. Field, J. Listening in the Language Classroom; Cambridge University Press: Cambridge, UK, 2009.

6. Rost, M. Listening in Language Learning; Longman: Harlow, UK, 1990.

7. Underwood, M. Teaching Listening; Harlow: Longman, UK, 1989. 
8. Anderson, R.; Klofstad, C. Preference for Leaders with Masculine Voices Holds in the Case of Feminine Leadership Roles. PLoS ONE 2012, 7, e0051216. [CrossRef] [PubMed]

9. Pulverness, A. English Teaching Essentials-Literature. MEP 2003, $29,40$.

10. Artyushina, G.; Baguzina, E.; Plekhova, O.; Sheypak, O. Developing communicative competence through Internet and digital technologies. In The Magic of Innovation. New Techniques and Technologies in Teaching Foreign Languages; Kryachkov, D.A., Yastrebova, E.B., Kravtsova, O.A., Eds.; Cambridge Scholars Publishing: Newcastle upon Tyne, UK, 2015; pp. 43-67. ISBN 978-1-4438-7271-3.

11. Prensky, M. Digital Natives, Digital Immigrants. On Horiz. 2001, 9, 1-6. [CrossRef]

12. Adams, C. Geek's guide to teaching in the modern age. Instructor 2006, 115, 48-51.

13. Belias, D.; Sdrolias, L.; Kakkos, N.; Koustelios, A. Traditional teaching methods vs. Teaching through the application of information and communication technologies in the accounting field: Quo vadis? ESJ 2013, 9, 28.

14. Renau Renau, M.L. A review of the traditional and current language teaching methods. IJIRES 2016, 3, 82-88.

15. Darmi, R.; Albion, P. A review of integrating mobile phones for language learning. In Proceedings of the 10th International Conference Mobile Learning, Madrid, Spain, 28 February-2 March 2014; International Association for Development of the Information Society: Algarve, Portugal, 2014; pp. 93-100.

16. Warlick, D. Podcasting. Technol. Learn. 2005, 26, 70.

17. Artyushina, A.; Artyushina, G.; Sheypak, O. Motivation in technical higher education. In Local Identity-Global Awareness Engineering Education Today, Proceedings of the 33rd International Symposium IGIP/IEEE/ASEE, Fribourg, Switzerland, 27-30 September 2004; University of Applied Sciences of Western Switzerland: Delémont, Switzerland, 2004; pp. 746-750.

18. Computerra. Available online: www.computerra.ru (accessed on 9 April 2018).

19. ESLpod. Available online: www.eslpod.com (accessed on 12 April 2018).

20. Artyushina, G.G.; Sheypak, O.A.; Golov, R.S. Podcasting as a Good Way to Learn Second Language in e-Learning. In Proceedings of the IC4E'17, Kuala Lumpur, Malaysia, 5-7 January 2017; pp. 51-55. [CrossRef]

(C) 2018 by the authors. Licensee MDPI, Basel, Switzerland. This article is an open access article distributed under the terms and conditions of the Creative Commons Attribution (CC BY) license (http:/ / creativecommons.org/licenses/by/4.0/). 